\title{
A Comparative Study to Determine the Outcome of Hepatic Encephalopathy who Have A Past History of Hepatic Encephalopathy And or Upper Gastrointestinal Bleeding Versus Who Have Not Such Using 7 Days Therapy of Rifaximin And or Lactulose.
}

\author{
*Dr.Shyamal Kanti Pal ${ }^{1}$,Dr.Subhrajyoti Naskar ${ }^{2}$,Dr.Gauranga biswas ${ }^{3}$, \\ Dr.Jadab Kumar Jana ${ }^{4}$,Dr.SK.Jeauddin ${ }^{5}$,Dr.Soumitra Kumar Ghosh ${ }^{6}$ \\ ${ }^{1}$ RMO Department Of Medicine, Malda Medical College, Malda \\ ${ }^{2}$ Assistant Professor, Department Of Community Medicine, Malda Medical College, Malda. \\ ${ }^{3,4}$ Assistant Professor, Department Of Paediatrics, Malda Medical College, Malda. \\ ${ }^{5}$ RMO, Department of paediatrics, Malda Medical College,Malda. \\ ${ }^{6}$ Associate Professor,Department Of Radiology, Malda Medical College, Malda. \\ Corresponding author: *Dr.Shyamal Kanti Pal
}

\begin{abstract}
:
Introduction: Hepatic encephalopathy is a reversible neuro-psychiatric syndrome occurring in majority of patients with decompensated chronic liver disease(CLD). Prognosis of Hepatic encephalopathy (HE) depends upon past h/o hematemesis/ melena and HE but not related to the aetiology of CLD. Rifaximin and lactulose have similar efficacy for treatment of acute HE. Purpose of this study is to compare the effectiveness of 3 modes of treatment for 7 days in terms of clinical improvement / deterioration who have or have not past h/o hematemesis/melenaand or HE.

Material and methods: After ethical clearance and consent from patient parties, 90 patients of HE of any cause and grade with or without past h/o hematemesis/melena and or HE, were categorise into different grades according to West Haven criteria and randomised to treat for 7 days with divided doses by either rifaximin 30 patients, lactulose 30 patients, rifaximin plus lactulose 30 patients. At the end, clinical improvement and deterioration were noticed.

Results: Alcoholic CLD (63.33\%) was the commonest. Clinical deterioration were commoner in chronic HCV (66.67\%) than chronic HBV, alcoholic CLD. Patients with past h/o hematemesis /melena, clinical deterioration and improvement were $26.92 \%$ and $73.08 \%$ but without such, clinical deterioration and improvement were $2.63 \%$ and $97.37 \%$. Patients with past h/o HE, clinical deterioration and improvement were $31.25 \%$ and $68.75 \%$ but without such past illness, clinical deteriorations and improvements were 0 and $100 \%$.

Conclusion: So clinical outcome is better in patients of HE without past h/o HE and hematemesis/melena. Keyword: Hepatic encephalopathy, chronic liver disease ,Rifaximin,Lactulose
\end{abstract}

\section{Introduction}

Hepatic encephalopathy is a potentially reversible neuro-psychiatric and functional syndrome occurring in $50 \%-70 \%$ of patients with advanced liver disease and or porto-systemic shunting [1].It occurs in presence of insufficient hepatic clearance of toxic products absorbed from intestine resulting in neuro-chemical abnormalities after crossing blood brain barrier[2] Although occurrence of an episode of hepatic encephalopathy appears to be unrelated to the cause of cirrhosis [3], increases in frequency and severity of such episode predict an increased risk of death [4,5].Clinical manifestation of HE range from altered mental status to deep coma[6]. Recurrent episodes of hepatic encephalopathy may be triggered by non-compliance to therapy or precipitated by infection, gastrointestinal bleeding, constipation, high protein diet, dyselectrolytaemia.Current treatment strategies are aimed to reduce serum ammonia by rifaximin or lactulose /lactitol and correcting the precipitating factors. The purpose of this study is to compare the outcome of hepatic encephalopathy in terms of short term mortality and clinical improvement who have a past h/o upper G.I. bleeding and or hepatic encephalopathy versus who have no such past history with7days therapy of lactulose and or rifaximin . 


\section{Materials And Methods}

Three modalities of treatment in hepatic encephalopathy are :Group- A:lactulose(60 gm/day) 30 Patients, Group-B: Rifaximin(1200mg/day) 30 Patients Group-C : Lactulose (60gm/day) with Rifaximin (1200mg/day) 30 Patients

Study Type: Prospective study

Study Design: a) Allocation - Randomised, b) End point classification - Efficacy study,c) Model - Parallel assignment,d)Primary purpose Medical treatment and data analysis

Study Area: Indoor medicine ward, R. G. Kar Medical College and Hospital, Kolkata -700004.,

Study Population: Adult (>18years) admitted patients of hepatic encephalopathy of any grade of any cause with decompensated chronic liver disease.

Study Period: 6 months.

Sample Size: a) rifaximin and lactulose - 30 patients, b) lactulose alone - 30 patients, c) rifaximin alone - 30 patients.

Sample Design Patients were randomised to treat with either Rifaximin and Lactulose / Lactulose / Rifaximin for 7 days with the doses -a) Rifaximin - $1200 \mathrm{mg}$. /day (400 mg. thrice a day) b) Lactulose- 60 $\mathrm{gm} /$ day(20 gm. thrice a day) c) Rifaximin $-1200 \mathrm{mg} /$ day (400 $\mathrm{mg}$ thrice a day)and Lactulose $60 \mathrm{gm} / \mathrm{day}(20 \mathrm{gm}$ thrice a day)

Eligibility Criteria: a) INCLUSION CRITERIA:adult (>18years) admitted patients of both sexes, decompensated chronic liver disease of any cause, hepatic encephalopathy of any grade.b) EXCLUSION CRITERIA:hepatic encephalopathy patients complicated with haematemesis and or melena, hepato-renal syndrome, hepato -pulmonary syndrome, hepato-cellular carcinoma, spontaneous spontaneous bacterial peritonitis, dyselectrolytaemia,other metabolic encephalopathies, severe comorbidities such as congestive cardiac failure, pulmonary diseases, kidney diseases, neuro-psychiatric illness,sepsis, h/o allergy with rifaximin and or lactulose.

Paramrters To Be Compared: Asterixis, mental function, sleep problem

Ethical Clearance: Approval from Ethical Committee, R. G. Kar Medical College was taken. Consent was taken from patient or patient relatives

Study Tools:1)Clinical history : H/o alcoholism, h/o jaundice, hematemesis, melena ; h/o ascites; h/o sleep problem/ abnormal behaviour / abnormal movement in the distal part of limbs 2)past h/o:similar illness /hematemesis / melena 3) Clinical examination : as per proforma (annexure-3), general survey, systemic examination including vitals., West Haven criteria of altered mental status in hepatic encephalopathy [9] Categorisation of patients into different groups according to West Haven criteria (also called Conn Score) then randomisation of the patients with assignment to treat the patients with rifaximin and lactulose or lactulose or rifaximin for 7days. After treatment short term mortality, clinical deterioration, clinical improvement are noticed.

\section{Results}

The number and percentage of patients of different etiology of decompensated chronic liver diseases . Alcoholic chronic liver diseases $(63.33 \%)$ was the most common cause in the study,followed by cryptogenic chronic liver diseases (20\%), chronic HBV infection (13.33\%), chronic HCV infection (3.33\%) (table 1). The cause of clinical deterioration in chronic decompensated liver diseases with hepatic encephalopathy. More common causes of deterioration in our study were chronic HCV $(66.67 \%)$ and chronic HBV (25\%) infection but among the total clinical deteriorations alcoholic chronic liver disease was maximum. But this is not statistically significant $(\mathrm{p}=0.789)$.(Table 2$)$

The patients with past h/o upper G.I .bleeding, clinical deterioration occurred in $26.92 \%$ and improvement was $73.08 \%$. But among the patients without having past h/o upper G.I. bleeding, clinical deteriorations occurred only in $2.63 \%$ of cases and clinical improvements occurred in $97.37 \%$. This differences of clinical outcome are statistically significant $(\mathrm{p}=0.002)$. (Table 3$)$ The patients with past $\mathrm{h} / \mathrm{o}$ hepatic encephalopathy,clinical deterioration occurred in $31.25 \%$ and corresponding percentage of improvement was $68.75 \%$. But among the patients without having past h/o hepatic encephalopathy, clinical deteriorations were nil and clinical improvements were 100 percent and statistically significant (p $=0.000)$. (Table 4) The figure 1 represents that out of 90 study patients, $48(53.33 \%)$ patients had past h/o hepatic encephalopathy, $52(57.77 \%)$ had past h/o upper G.I. bleeding and $22(24.44 \%)$ had past h/o neither hepatic encephalopathy nor upper G.I. bleeding. Figure 2 shows the distribution of patients according to presence of past h/o hepatic encephalopathy, upper G.I. bleeding or none, where past history of upper gastro intestinal bleeding constitute the most. 
Figure 3 shows distributions of cause specific clinical deteriorations where among the total clinical deteriorations alcoholic chronic liver disease is maximum.

\section{Discussion}

Types of chronic liver diseases: In this study, alcoholic chronic liver diseases(63.33\%)was the most common cause of decompensated chronic liver diseases, followed by cryptogenic chronic liver diseases (20\%), cirrhosis of liver due to chronic HBV infection (13.33\%), HCV infection (3.33\%). In Western countries, alcohol abuse remains the most common aetiology of chronic liver diseases with hepatic encephalopathy $[11,12]$. But in another study,it is revealed that occurrence of hepatic encephalopathy appears to be unrelated to the cause of cirrhosis[3]

Cause specific mortality after treatment: In the study, maximum clinical deteriorations occurred in patients of alcoholic chronic liver disease bu the cause specific clinical deteriorations were more in patients of chronic liver diseases due to chronic HCV infection (66.67\%) and chronic HBV infection (25\%).But this apparent differences were not statistically significant $(p=0.0789)$. As the number of patients in different group of patients of decompensated chronic liver diseases were small in size, it is difficult to draw any conclusion. A cross sectional study, published in BMC Gastroenterlogy 2008; 8: 46, showed that type and etiology of cirrhosis of liver are not related to presence of hepatic encephalopathy or not related to quality of life [3].

Past illness and outcome: About half of the study patients (about 53.33\%) had past h/o hepatic encephalopathy and $57.77 \%$ of the patients had past $\mathrm{h} / \mathrm{o}$ hematemesis and or melena. Multiple studies reveal that increases in frequency and severity of such episode of hepatic encephalopathy predict an increased risk of death $[4,5]$.

From our study it was found that clinical deterioration occurred more in patients having past h/o upper G.I. bleeding $(26.92 \%$ than in patients without past $\mathrm{h} / \mathrm{o}$ upper G.I.bleeding $(2.63 \%)$ and corresponding clinical improvements were $73.08 \%$ and $97.37 \%$ respectively. This differences of clinical outcome in presence or absence of past $\mathrm{h} / \mathrm{o}$ upper G.I. bleeding are statistically significant $(\mathrm{p}=0.002)$.

The patients with a past $\mathrm{h} / \mathrm{o}$ similar illness, i.e, hepatic encephalopathy resulted in clinical deteriorations ( $31.25 \%)$. On the other hand the patients without past $\mathrm{h} / \mathrm{o}$ similar illness did not suffer from any clinical deterioration and their corresponding clinical improvements were $68.75 \%$ and $100 \%$ respectively. This is also statistically significant $(\mathrm{p}=0.000)$; so past $\mathrm{h} / \mathrm{o}$ upper G.I. bleeding and hepatic encephalopathy have significant impact on clinical outcome . There is a study about prognostic significance of hepatic encephalopathy, published in J. Heptol 1999 ; 30: 890-5, which reveals that frequency and severity of hepatic encephalopathy predicts an increased risk of death [ 4,5].

\section{Conclusion}

This study it is revealed that clinical outcome was significantly better in patients of hepatic encephalopathy without past h/o hepatic encephalopathy and upper G.I. bleeding.

Declaration Of Conflicting Interest: There is no conflict of interest.

\section{References}

[1]. Schfer DF, Jones EA. Hepatic encephalopathy. In Zakim D, Boyer TD, editors. Hepatology. A Textbook of liver disease . Philadelphia: W. B. Saunders, $1990 ; 447-460$

[2]. Abou-Assi S, Vlahcevic ZR. Hepatic encephalopathy. Metabolic consequence of cirrhosis often is reversible. Postgrad. Med. 2001; 109: 52-54, 57-60, 63-65.

[3]. Kalaitzakis E, Josefsson A, Bjornsson E. Type and etiology of liver cirrhosis are not related to the presence of hepatic encephalopathy or health related quality of life: a cross sectional study. BMC Gastroenterology 2008; 8:46

[4]. Bustamante J, Rimola A,Ventura P,et.al. Prognostic significance of Hepatic encephalopathy in patients with cirrhosis. J Heptol 1999;30:890-5

[5]. Stewart CA, Malinchoc M, Kim WR predictor of survival in patients with end stage liver disease. Liver Transpl 2007;13:1366-71.

[6]. de Melo RT, Charneski L, Hilas O. Rifaximin for the treatment of hepatic encephalopathy. Am J Health Syst Pharm 2008; 65: 818822Conn HO. Liberthal MM, The hepatic coma syndrome and lactulose. Balti-more: Williams \& Willkins , 1979

[7]. Ferenci P, Lockwood A, Mullen K, Tarter R, Weissenborn K, Blei AT. Hepatic encephalopathy-- defination, nomenclature, diagnosis and quantification: final report of the working party at the $11^{\text {th }}$. World Congress of Gastroenterology 2002; 35: 716-21

[8]. Mas A, Rodes J, Sunyer L, Planas R,Vargas V, et. al. Comparison of rifaximin and lactitol in the treatment of acute hepatic encephalopathy : results of a randomized, double-blind, double-dummy, controlled clinical trial. J Hepatol 2003;38:51-8

[9]. World J. Gastroenterology,2012 February $28 ; 18$ (8) :766-777

[10]. Teasdale G, Jennet B . Assessment of coma and impaired consciousness, A Practical Scale, Lancet 1974; $2: 81-84$

[11]. Huh K, Choi SY, Whang YS, Lee DS. Prevalence of viral hepatitis markers in Korean patients with hepatocellular carcinoma. J Korean Med Sci 1998;13:306-10

[12]. Mandayam S, Jamal MM, Morgan TR. Epidemiology of alcoholic liver dise[10]. Teasdale G, Jennet B . Assessment of coma and impaired consciousness, A Practical Scale, Lancet 1974; $2: 81-84$ 
Tables 1.Distribution of causes decompensated chronic liver diseases.

\begin{tabular}{|l|l|l|}
\hline Cause of chronic liver diseases & Number & \multicolumn{1}{|c|}{ Percentage } \\
\hline Alcoholic & 57 & 63.33 \\
\hline Chr. HBV infection & 12 & 13.33 \\
\hline Chr. HCV infection & 03 & 03.33 \\
\hline Cryptogenic & 18 & 20.00 \\
\hline Total & 90 & 100.00 \\
\hline
\end{tabular}

Table-2. Distribution of cause specific clinical deteriorations .

\begin{tabular}{|l|l|l|}
\hline Causes of chronic liver diseases & $\begin{array}{l}\text { Number of clinical deterioration } \\
(\mathbf{n = 1 5})\end{array}$ & Percentage \\
\hline Alcoholic $(\mathrm{n}=57)$ & 07 & 12.28 \\
\hline Cryptogenic $(\mathrm{n}=18)$ & 03 & 16.67 \\
\hline Chr. HBV $(\mathrm{n}=12)$ & 03 & 25.00 \\
\hline Chr. HCV $(\mathrm{n}=03)$ & 02 & 66.67 \\
\hline Total $(\mathrm{n}=90)$ & 15 & 16.67 \\
\hline $\mathrm{X}^{2}=6.79, \mathrm{df}=3, \mathrm{p}=0.0789$ &
\end{tabular}

$\mathrm{X}^{2}=6.79, \mathrm{df}=3, \mathrm{p}=0.0789$

Table - 3. Comparison of clinical outcomes according to past illness of upper G.I. bleeding

\begin{tabular}{|c|c|c|}
\hline Past h/o U.G.I. bleeding & Clinical deterioration & Clinical improvement \\
\hline Yes $(\mathrm{n}=52)$ & $14(26.92 \%)$ & $38(73.08 \%)$ \\
\hline No $(\mathrm{n}=38)$ & $01(02.63 \%)$ & $37(97.37 \%)$ \\
\hline Total $(\mathrm{n}=90)$ & $15(16.67 \%)$ & $75(83.33 \%)$ \\
\hline
\end{tabular}

$\mathrm{X}^{2}=9.33, \mathrm{p}=0.002$

Table - 4. Comparison of clinical outcome according to similar past illness (hepatic encephalopathy) in the past.

\begin{tabular}{|c|c|c|}
\hline $\begin{array}{lcc}\text { Past } & \mathbf{h} / \mathbf{o} & \text { hepatic } \\
\text { encephalopathy } & \\
\end{array}$ & Clinical deterioration & Clinical improvement \\
\hline Yes $(\mathrm{n}=48)$ & $15(31.25 \%)$ & $33(68.75 \%)$ \\
\hline No $(n=42)$ & $00(00 \%)$ & $42(100 \%)$ \\
\hline Total $(\mathrm{n}=90)$ & $15(16.67 \%)$ & $75(83.08 \%)$ \\
\hline
\end{tabular}

$\mathrm{X}^{2}=15.75, \mathrm{p}=0.000$

Figure-1. Pie-distribution of causes of decompensated chronic liver diseases.

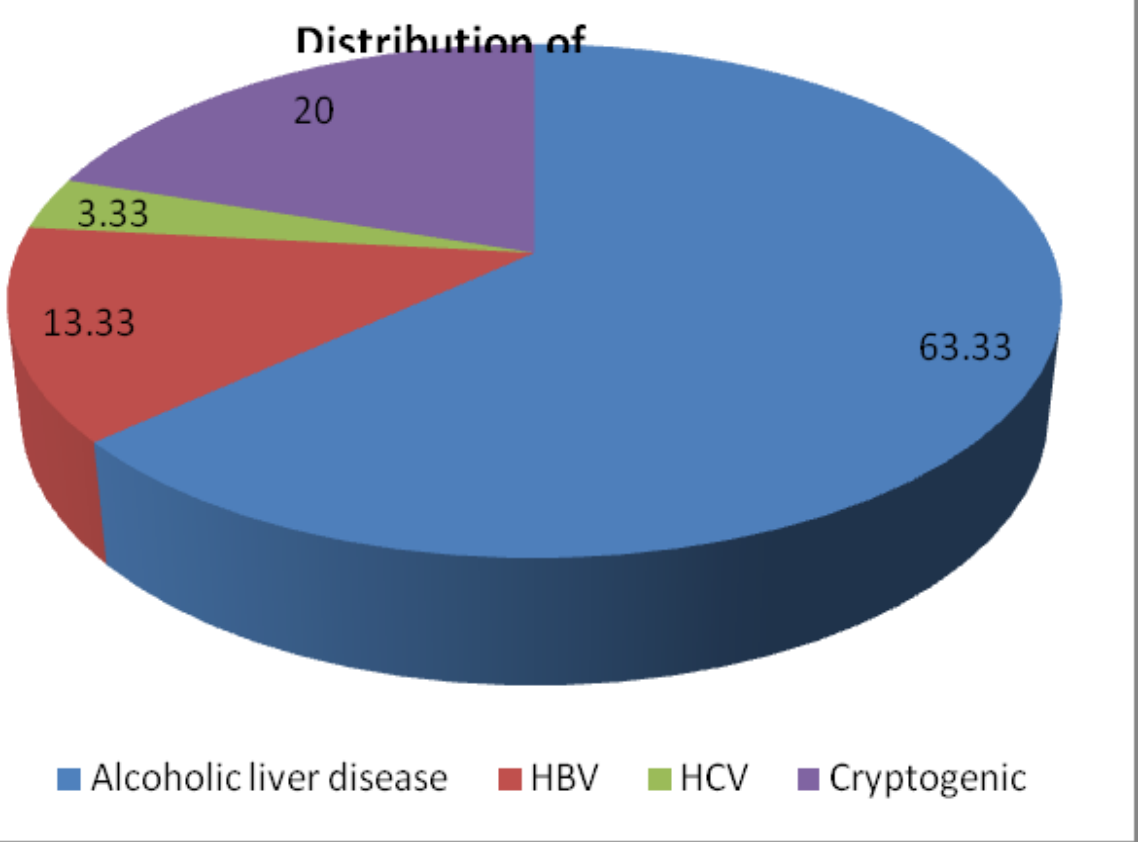


Figure -2. Distribution of patients according to presence of past h/o hepatic encephalopathy, upper G.I. bleeding or none.

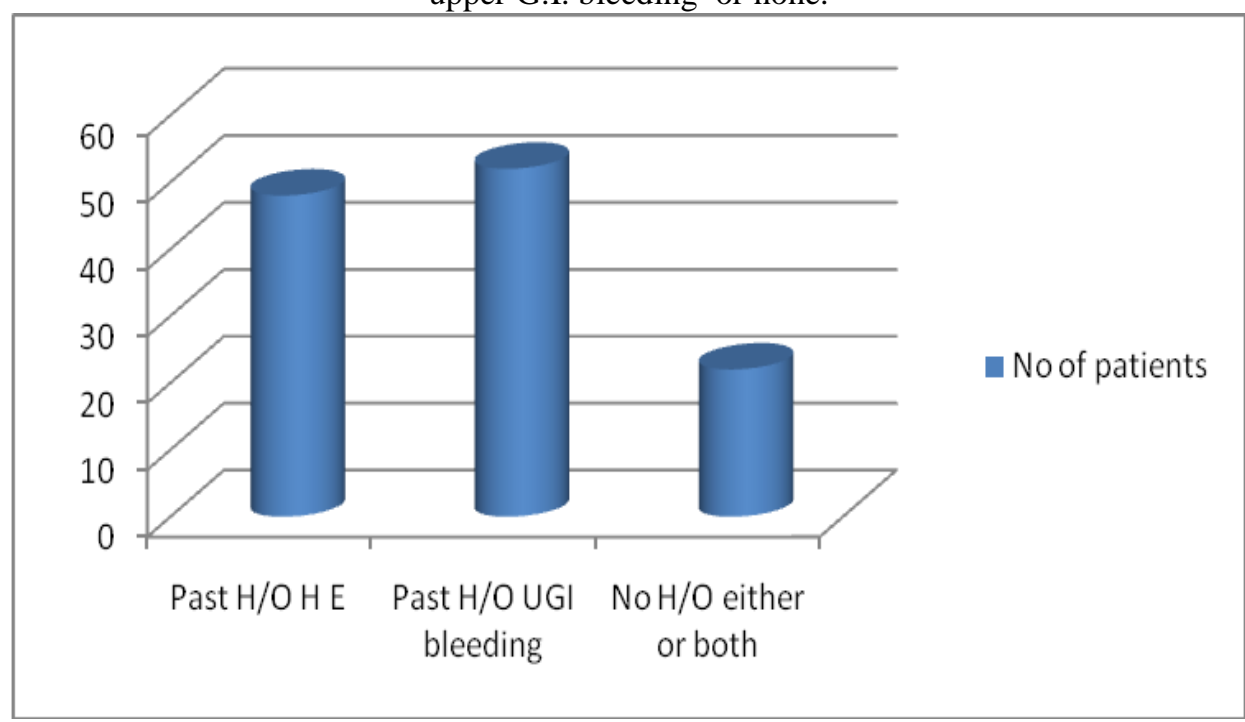

Figure -3. Distributions of cause specific clinical deteriorations.

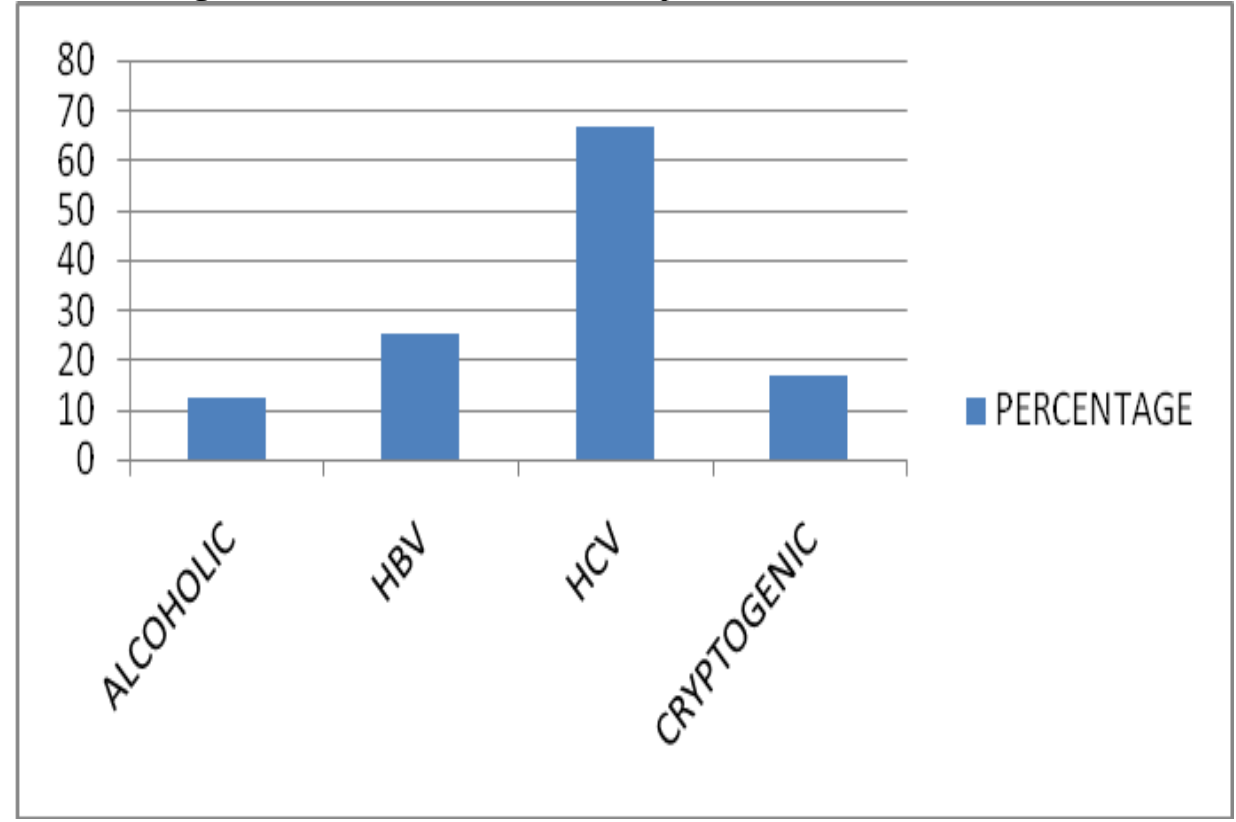

*Dr.Shyamal Kanti Pal. "A Comparative Study to Determine the Outcome of Hepatic Encephalopathy who Have A Past History of Hepatic Encephalopathy And or Upper Gastrointestinal Bleeding Versus Who Have Not Such Using 7 Days Therapy of Rifaximin And or Lactulose." IOSR Journal of Dental and Medical Sciences (IOSRJDMS) 16.7 (2017): 50-54. 